\title{
Bridging the gap: blending spatial skills instruction into a technology teacher preparation programme
}

\author{
Diarmaid Lane ${ }^{1}(1) \cdot$ Sheryl Sorby ${ }^{2}(\mathbb{0}$
}

Accepted: 3 July 2021 / Published online: 4 August 2021

(c) The Author(s) 2021

\begin{abstract}
In recent years, there has been a surge in research in spatial thinking across the international community. We now know that spatial skills are malleable and that they are linked to success across multiple disciplines, most notably Science, Technology, Engineering and Mathematics (STEM). While spatial skills have been examined by cognitive scientists in laboratory environments for decades, current research is examining how these skills can be developed in field-based environments. In this paper, we present findings from a study within a Technology Teacher preparation programme where we examined first-year students' spatial skills on entry to university. We explain why it was necessary to embed a spatial skills intervention into Year 1 of the programme and we describe the impact that this had on students' spatial scores and on academic performance. The findings from our study highlight a consistent gender gap in spatial scores at the start of the first-year with female students entering the Technology Teacher preparation programme at a lower base level than male students. We describe how we integrated spatial development activities into an existing course and how an improvement in spatial scores and overall course performance was observed. The paper concludes by discussing the long-term sustainability of integrating spatial interventions within teacher preparation programmes while also highlighting the importance of future research to examine spatial skills as a fundamental component of technological capability.
\end{abstract}

Keywords Spatial thinking · Instruction · Intervention · Visualisation · Teacher preparation

\section{Introduction}

In a 2006 national report in the USA, spatial thinking was described as 'a missing link' in the school curriculum (NRC, 2006). The report stated that a concerted effort to better integrate and infuse spatial thinking into schools could enable students to engage at a deeper

Diarmaid Lane

Diarmaid.Lane@ul.ie

1 School of Education, SR2002, Schrödinger Building, University of Limerick, Limerick V94 T9PX, Ireland

2 College of Engineering and Applied Science, University of Cincinnati, Cincinnati, OH, USA 
level in their learning and it could also help foster a new generation of spatially literate students.

The Programme for International Student Assessment (PISA) is often cited by researchers when comparing science, mathematics, reading, and problem-solving skills of 15/16 year olds across the world (Anderson et al., 2007; Herborn et al., 2020). 'Space and Shape' is a component of 'Mathematical Literacy' in PISA and it contains elements that are spatial in nature with a focus on geometry, spatial visualization, measurement and algebra (OECD, 2014). When Space and Shape was last assessed in 2012, Ireland, the USA, the United Kingdom, Sweden, Turkey and Spain were among the countries that performed significantly below the OECD average in that component. Shanghai-China was the best performing country across the OECD for Space and Shape and they were joined by countries such as Korea, Netherlands, Germany and Australia in performing significantly above the OECD average (OECD, 2014).

In recent years, research has found that spatial skills are malleable and they can be developed with targeted instruction (Uttal et al., 2013a, 2013b). It is now clear that strong spatial skills are positively correlated with success in STEM disciplines (Hegarty et al., 2017; Wai et al., 2009). Some studies have found that females tend to perform lower than males in timed spatial tests (Casey et al., 1997; Lippa et al., 2010; Sorby, 2009) and this has triggered attention from policy makers who are keen to address the gender imbalance favouring males that persists in STEM related courses and professions (Card \& Payne, 2020; Yonghong, 2008).

In this paper, we provide our experience from a Technology Teacher preparation programme at the University of Limerick where high numbers of students were failing a 'Design and Communication Graphics' (DCG) course in their first year, and were not directly progressing to the second year of their programme. Concerns were raised by university administration in relation to retention targets for the programme not being met over a number of consecutive years. Based on the growing body of research evidence around the correlation between spatial skills and performance in STEM, combined with the low ranking of Irish adolescents in Space and Shape, we examined the spatial thinking skills of first year students entering the programme over a 4 year period to establish if low levels of spatial skills could be a factor in the poor course performance. This paper should be of interest to researchers, policy makers and educators especially in countries which are among the lower ranked nations for Space and Shape, as measured by PISA. The importance of our study is supported by Atit et al. (2018) who highlight the need to work with teachers in supporting their spatial skills development as teachers spatial skills may influence the development of students spatial skills in their classrooms.

\section{An overview of spatial thinking}

As human beings living on planet earth, we exist in space every minute of every day and without space our world would be inconceivable (Newcombe \& Shipley, 2015). In its simplest form, we can think about space in a 2-dimensional, or 2D, format. Arrangements of lines and points on flat surfaces form geometric shapes including; squares, rectangles, triangles, circles, irregular polygons and so on. Rising up from a flat or planar surface, objects can occupy a 3-dimensional, or 3D, volumetric space. Our world contains an abundance of 3D spatial objects ranging from basic solids such as cubes, cones and pyramids, to the atom, the human body, buildings, an urban landscape, and the vast ocean floor. As 
human beings, we live in and navigate our way through spaces on a daily basis, and we are constantly interacting with a variety of spatial objects.

Considering the prevalence of space and spatial objects in all of our daily lives and the surge in technologies used to communicate spatial information, there is a need for a concerted effort to integrate strategies and tools for spatial skill development across disciplines in schools and colleges (Janelle et al., 2014; NRC, 2006; Wai \& Uttal, 2018). This is becoming increasingly more important when one considers the performance (mentioned earlier) of countries across the world in the Space and Shape component in PISA.

Fundamentally, spatial thinking concerns the position of objects, their shapes, their relations to each other, and the paths they take as they move (Newcombe, 2010). Moore-Russo et al. (2012) succinctly describe three components for spatial literacy including; visualization, reasoning, and communication. Visualization helps people in creating cognitive representations, enabling them to see and understand the characteristics of spatial objects in their mind. When visualizing a spatial object it can be physically present and a person can improve their understanding about the spatial properties of that object by physically manipulating it or moving around it and viewing it from different orientations. There are also times when the spatial object might not be physically present and it could be described on a flat surface such as a drawing, map, or another form of image. This requires a higher level of skill to be able to understand the conventions in which the object is communicated and from this visualize the described object. Reasoning about a spatial object, involves being able to mentally manipulate internal representations, imagine changes to objects such as cut sections, form judgements, and make conclusions. The communication component of spatial thinking involves being able to exchange information through interactions with oneself or others by describing spatial objects and any manipulation of these using tools such as; sketching, computer modelling, physical modelling, gesturing, and verbal dialogue.

While spatial thinking is relevant across many disciplines, it is considered a fundamental skill within the STEM domain (Smith, 1964). In recent years, a number of research studies have reported that spatial thinking is an important component within STEM and that strong spatial skills are positively correlated with high grades, most notably in Mathematics (Hegarty et al., 2017; Uttal et al., 2013a, 2013b; Wai et al., 2009). In a longitudinal study conducted by Wai et al. (2009), it was found that the likelihood of earning an advanced degree in STEM is directly related to a person's spatial ability. Perhaps one of the more significant research findings in recent years is that spatial skills are a predictor of success in STEM disciplines (Stieff \& Uttal., 2015). These findings combined with the knowledge that spatial skills can be taught and are malleable has led to a surge in interest in the area across the international research community.

\section{Spatial thinking in schools and colleges}

In an OECD Working Paper, Newcombe (2017) described two main strategies for developing spatial thinking skills including; a 'direct training' approach and a 'just-in-time' approach. The 'direct training' approach involves the identification of students who struggle with spatial thinking and the completion of a set of developmental activities designed to alleviate these. An example of a 'direct training' intervention is the spatial thinking course designed by Sorby (2011) for Engineering students which includes specific activities across ten modules involving the use of physical block cubes, a workbook and digital software. This intervention has been shown to be effective in helping weak spatial learners 
in their first year of Engineering studies, and it has been found to help female students in particular resulting in higher grades and improved retention (Veurink \& Sorby, 2017). The 'just-in-time' approach involves the integration of spatial tools and strategies into existing curricula as the need arises. Examples of just-in-time tools and strategies include; the use of sketching, physical models, gesture, and dynamic digital software and applying these strategies on an as-needed basis in the curriculum (Gagnier et al., 2016; Goodchild \& Janelle, 2010; Stieff et al., 2016).

As the attention of researchers has turned to examining the nature of spatial thinking in field-based environments, we are beginning to learn more about the challenges and opportunities for its integration in schools and colleges. Project TALENT was a large national study conducted in the USA which tracked 4428 students who entered teacher preparation programmes after high school. In their report of this study, Atit et al. (2018) highlight that secondary STEM teachers had substantially stronger spatial skills than secondary non-STEM teachers and preschool/primary teachers. They describe the need for further research to examine if there is a relationship between teachers' spatial skills and student learning while also highlighting the need to investigate the effect of spatial training for teachers and the impact that this can have on their current or future students.

In contrast to the findings from Project TALENT, Moore-Russo et al. (2012) found in their work with pre-service and in-service Mathematics teachers at a large research university in the USA, that many teachers' spatial skills were underdeveloped and in particular the teachers struggled with dimensional reasoning. Furthermore, they reported that many of their participating teachers had poor vocabulary relating to spatial concepts and that misconceptions hindered their performance in spatial tasks. Staying within the field of Mathematics, Lowrie et al. (2017) examined the impact of a visuospatial training programme on elementary students' mathematics performance through an experimental study. Their findings showed that students' mathematics performance improved following the classroom-based intervention and they claim that this was the first such study to find this in an elementary school setting. In a recent study, Atit et al. (2020) examined the relationship between motivation for mathematics and spatial skills in middle school mathematics students and they found that both motivation and spatial skills interact significantly to predict student mathematics performance.

Moving to the Science domain, there is considerable interest in the role that spatial thinking plays in the study of Chemistry and Anatomy. In their work in Chemistry classrooms, Cooper et al. (2017) describe the important role of sketching as a fundamental enquiry activity that helps students with model-based reasoning. Also supporting the importance of spatial thinking in Science, Hegarty (2014) highlights the correlation between spatial ability and performance in science programmes and she describes the need to better understand how students can be supported in working with and creating spatial representations. In their work with medical students, Gonzales et al. (2020) found that spatial training did not improve the spatial scores or anatomy test scores but they highlighted that spatial skills testing can help in highlighting students who may require additional academic support.

In relation to Technology Education, several studies have looked at different aspects of spatial thinking in schools and teacher preparation programmes in recent years with some of these studies published in this journal. In a recent study by Šafhalter et al. (2020) it was found that the integration of SketchUp (a digital modelling software) into a 'Technology and Technics' class for 11-14 year olds resulted in improved spatial visualization scores of students. Lin (2016), in their work with industrial design students at a university in Taiwan found that students' spatial visualization and spatial relations scores improved 
after receiving design training and they describe the need to extend research in this area to examine if students' creativity increases through design training. Similarly, Goktepe Yildiz and Ozdemir (2020) in their work with middle school students found that completing engineering design-based activities improved students' spatial abilities.

Other research stemming from the Technology and Engineering Education domain has offered insights into different aspects of spatial cognition. Strong spatial skills are not only important to visualization but they also support 'thinking' when problem-solving (Duffy et al., 2020). Furthermore, strong spatial skills help to increase the capacity of working memory and reduce cognitive load during graphical problem-solving tasks (Buckley et al., 2019; Delahunty et al., 2020). Finally, it is worth noting that spatial skills have been of interest across the technology and design community for over 30 years, stemming back to the work of Price and Reid (1990) when they examined predictors of craftsmanship in young children.

Our review of the literature highlights that there is a growing body of research that is concerned with the nature of spatial thinking across the education landscape. We know that targeted spatial training can enhance spatial skills, but it is clear that enhanced spatial performance does not always correlate with success across all STEM disciplines. While spatial training has been shown to positively impact some aspects of academic performance, other variables are also at play including motivation (Atit et al., 2020), self-efficacy (Power \& Sorby, 2020), and spatial anxiety (Atit et al., 2018).

\section{Context of the study}

As described in the Introduction section of this paper, our study was concerned with addressing a high failure rate in a Year 1, Design and Communication Graphics (DCG) course for first-year pre-service Technology teachers at the University of Limerick. Almost 1 in every 4 students (typically 35 out of 135) were awarded fail grades in DCG in their first year and this trend was persistent over a number of years. On examining the 2012 PISA results for Space and Shape, we felt that it would be worthwhile to examine first-year students' spatial skills on entry to the Technology Teacher preparation programme and to investigate if low spatial skills were a factor in the poor course performance.

The 4-year undergraduate programme qualifies teachers to teach in mainstream secondary schools with specialization in Construction Studies, Engineering, Technology, and DCG. Historically DCG was accepted by both university staff and students as a 'filtering mechanism' that 'weeded out' students who were going to have difficulty in progressing through the programme. It was often cited locally that the complex aspects around plane and descriptive geometry were difficult for many students to understand and visualize and that if students were not naturally good at spatial thinking, it would prove difficult for them to progress to graduation. Thus, the DCG course, not by design, became a filter to sort the students into two bins - those who could or could not become future technology teachers. Based on our review of the literature, the research questions for this study were as follows:

1. What are the baseline spatial skills of students on entry to the Technology Teacher preparation programme?

2. What impact would a spatial intervention have on students' spatial skills?

3. What impact would a spatial intervention have on course performance? 


\section{Evaluation of first year baseline spatial skills}

In this section of the paper we describe how we evaluated students' spatial skills at the beginning of their first year of study. We conducted this evaluation over four consecutive years with four separate cohorts of first-year students. Several different measures of spatial ability were considered for use including; the Mental Cutting Test (MCT) (CEEB, 1939), Differential Aptitude Test (DAT) (Bennett et al., 1973), and the Purdue Spatial Visualization Test of Rotations (PSVT:R) (Guay, 1977). In the end, the PSVT:R was selected for use in the study as this provided us with the means to compare our results with those obtained by others in the Technology and Engineering Education research space.

The PSVT:R instrument is widely used across the engineering education research community to measure the ability of students to mentally rotate geometric configurations through specified angles of rotation. Another factor in our decision to use this instrument was that it aligned with the types of spatial skills required in the study of DCG where students need to mentally view and rotate different 3D geometries such as cubes, cylinders, spheres, pyramids in both their original form and combined with other solids. The PSVT:R instrument has been used widely and Maeda and Yoon (2013) have conducted a meta-analysis on the test.

The test, containing 30 questions, was administered to all first-year students who were in attendance during their first DCG lecture in September of each year 2014 -2017. Instructions were provided on the inside page of the test booklet and students were allowed $20 \mathrm{~min}$ to complete the test. Over the 4-year period, a total of 405 students completed the test at the commencement of their studies. The results for these are detailed in Table 1 with scores disaggregated by gender. The minimum and maximum possible score for the test are 0 and 30 respectively.

The results over the 4-year period from 2014 to 2017 highlight that male students entering the programme consistently scored higher than females in the mental rotations test. This underperformance of females was not surprising as Irish females have also performed lower than males in the Space and Shape aspect of PISA (Close \& Shiel, 2009). Furthermore, the international literature also highlights that females often underperform on timed spatial tests (Maeda et al., 2013; Sorby et al., 1999) compared to their male counterparts. It should also be noted that the low proportion of females studying on the Initial Technology Teacher Education programme is representative of the percentage of females studying Technology subjects in Irish secondary schools. [Technology subjects at the secondary school level are still influenced by a legacy where males were encouraged to study Woodwork and Metalwork as preparation for entry into apprenticeship training]. While the current suite of Technology subjects espouse to cater for both genders, the majority of students who study them continue to be largely male. The consistent scores for each year group across the four years are also not surprising as during this time the secondary

Table 1 PSVT:R scores on entry to program 2014-2017

\begin{tabular}{|c|c|c|c|c|c|c|c|c|c|c|c|c|c|c|c|}
\hline & \multicolumn{3}{|c|}{2014} & \multicolumn{3}{|c|}{2015} & \multicolumn{3}{|c|}{2016} & \multicolumn{3}{|c|}{2017} & \multicolumn{3}{|c|}{$2014-2017$} \\
\hline & $\mathrm{n}$ & Mean & SD & $\mathrm{n}$ & Mean & SD & $\mathrm{n}$ & Mean & SD & $\mathrm{n}$ & Mean & SD & $\mathrm{n}$ & Mean & SD \\
\hline Male & 114 & 20.98 & 4.74 & 119 & 20.92 & 4.84 & 79 & 21.51 & 5.27 & 75 & 20.53 & 4.90 & 387 & 20.98 & 4.90 \\
\hline Female & 7 & 16.43 & 3.99 & 2 & 16.5 & 4.95 & 3 & 19.67 & 2.52 & 7 & 17.86 & 7.73 & 19 & 17.47 & 5.36 \\
\hline Total & 121 & 20.72 & 4.81 & 121 & 20.85 & 4.85 & 82 & 21.44 & 5.20 & 82 & 20.30 & 5.19 & 406 & 20.82 & 4.97 \\
\hline
\end{tabular}


school curriculum in Ireland has not changed significantly, therefore we would expect that the scores would be similar each year.

As this test was administered during the first week of semester 1, it is valid to compare the scores with other similar studies. In a recent study conducted at TU Dublin by Duffy et al. (2015) the spatial skills of 627 first year students enrolled on STEM courses were measured at the beginning of first year using the PSVT:R instrument. They recorded a mean score of 18.20. Sorby et al. (2018) in their work with Engineering students in the USA recorded a mean PSVT:R test score of 23.93. As the combined average score for the Technology Teachers in this study was 20.82, this highlights that Irish students are commencing their university studies with lower spatial skills than their US counterparts but the indicators are that the spatial skills of pre-service Technology teachers might be stronger than the STEM students at TU Dublin.

The data presented in this section provided us with evidence that a spatial intervention was warranted. In the next section we describe the spatial tools and strategies that were integrated into the course.

\section{Description of first semester DCG module}

Traditionally, Design and Communication Graphics 1 (DCG 1) was entirely focused on the study of plane and descriptive geometry with an emphasis on solving graphical problems using manual drafting equipment such as: drawing board, tee-squares, set squares, protractors, compasses, pencils and so on. Since 2007, a design element in which students use sketching and CAD (SolidWorks) to solve conceptual design problems, has been introduced to the study of DCG in Irish secondary schools.

In light of developments in the national curriculum in Ireland and the relatively low spatial skill levels of our first-year students, we decided to infuse the following into the module:

1. Spatial Thinking Intervention developed by Sorby (2011)

2. A supplemental series of $2 \mathrm{D}$ and $3 \mathrm{D}$ freehand sketching activities

The purpose of DCG 1 is to facilitate the development of students' understanding and knowledge of fundamental graphical concepts and principles while facilitating the exploration of these using different communication strategies such as freehand sketching and CAD. Both the Sorby intervention and supplemental sketching activities were infused within the module to complement the study of plane and descriptive geometry and the exploration of design. As these are both cited as appropriate tools/strategies for the development of spatial thinking, we hoped that their integration would help students in their graphical problem-solving exam at the end of the course as this was the main element that students were failing. Because the Sorby spatial skills intervention and the sketching activities were embedded within the module, all students regardless of their initial spatial skill score, were required to complete all elements.

Table 2 gives a breakdown of the course contact hours each week with a brief description of the purpose of each element. 


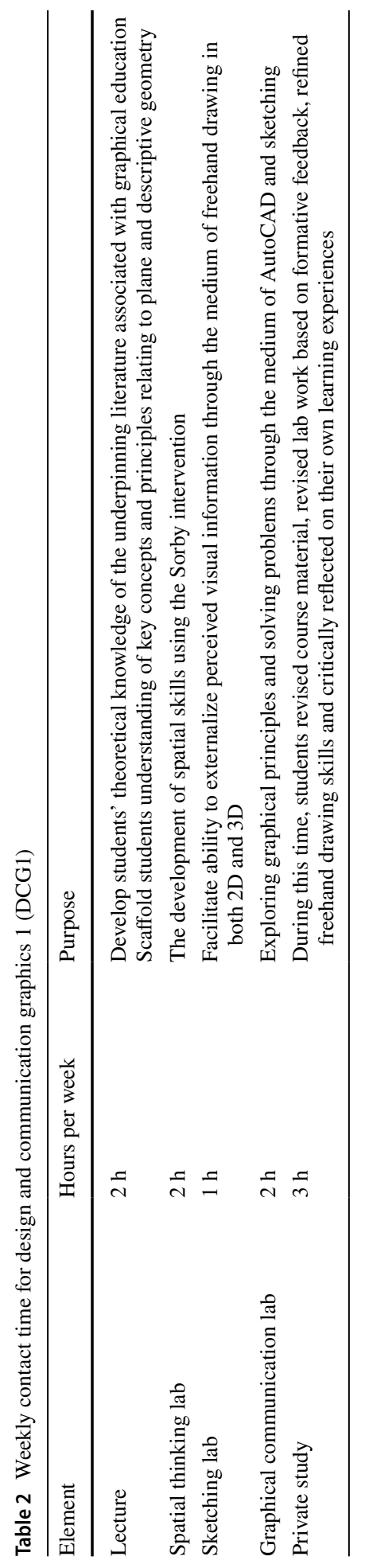




\section{Sorby spatial intervention integrated into DCG1}

The spatial skills intervention by Sheryl Sorby (2011) is comprised of a workbook, software, and snap cubes. The chapters, of which one was completed each week include the following:

1. Surfaces and Solids of Revolution

2. Combining Solid Objects

3. Isometric Drawings and Coded Plans

4. Orthographic Drawings

5. Inclined and Curved Surfaces

6. Flat Patterns

7. Rotation of Objects about a Single Axis

8. Rotation of Objects about Two or More Axes

9. Object Reflections and Symmetry

10. Cutting Planes

Further information on the workbook and accompanying software can be found in Sorby et al. (2018) and Power and Sorby (2020). One chapter of the intervention was assigned a two-hour slot each week. All students were provided with 15 snap-cubes which they used as a visual aid in several chapters in the workbook (Fig. 1).

Although many of the objects illustrated in the workbook can be constructed using snap-cubes, some objects with sloped surfaces could not be readily created. We used a rapid protype machine to create any irregular objects appearing in the workbook and these were provided for any students who struggled to visualize them. This approach helped the weaker students by being able to physically hold and manipulate the geometry in order to assist them in constructing and mentally rotating the visual mental image associated with the problem at hand. This scaffold was used on a limited basis and most students were able to independently visualize the objects without reference to the objects created using the rapid prototype machine (Figure 2).

Each lab group consisted of 20 students who demonstrated a mix of spatial skill levels. We encouraged all levels of students to reflect and critically think about their learning as they worked through the workbook. For example, in the revolve activity shown in Fig. 3, rather

Fig. 1 Classroom environment for the spatial skills intervention
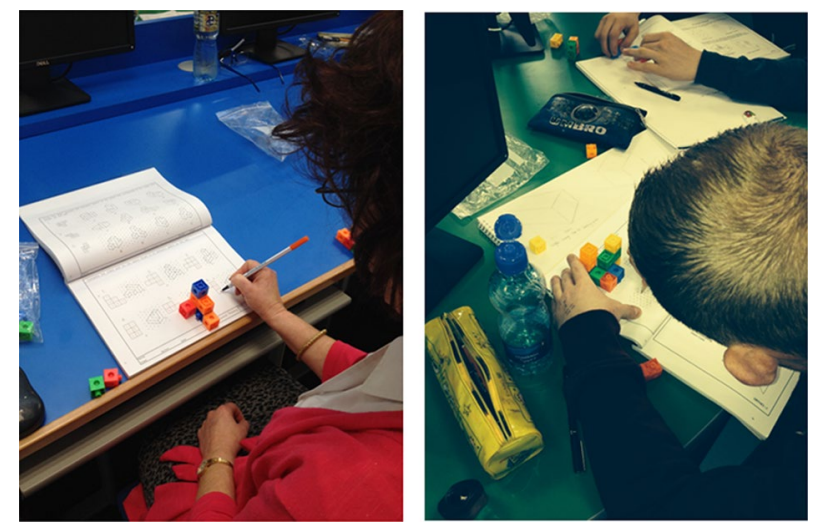


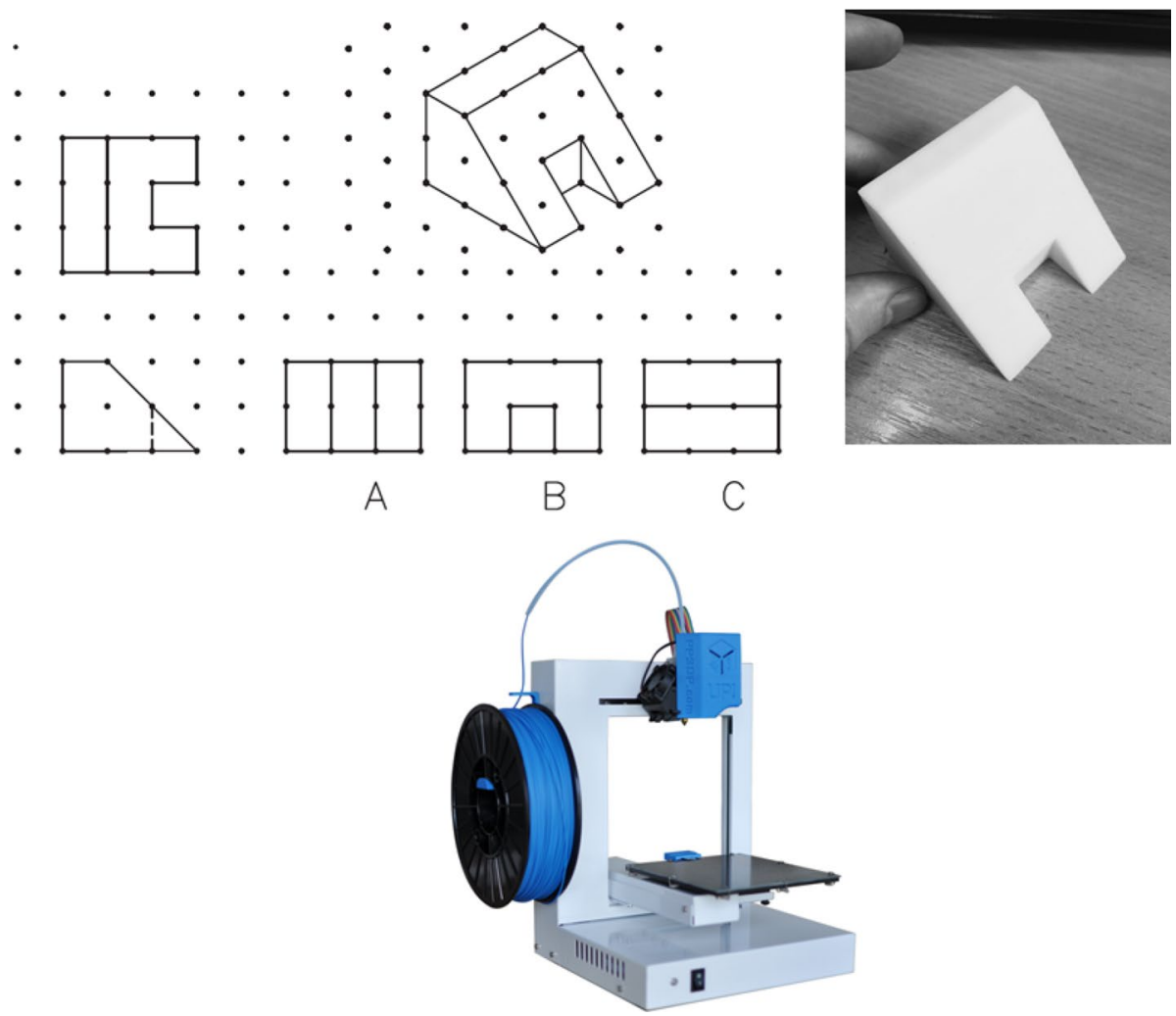

Fig. 2 Creating objects that typically cannot be formed using the snap-cubes

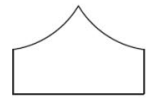

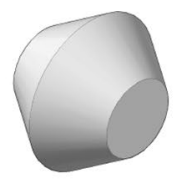

A

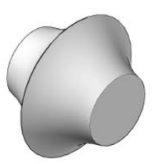

B

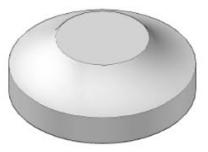

C

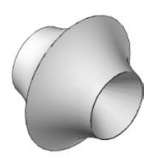

D

Fig. 3 Looking beyond the solution

than solely converging on the solution, students were encouraged to discuss in pairs or groups why the other three options were incorrect. Students typically sketched the profile of the objects or created 3D models in SolidWorks.

The workbook was graded on a Pass/Fail basis. Students were expected to have completed all activities each week and they were encouraged to cross-check their answers with each other. 


\section{Sketching intervention}

In the one hour sketching lab, the focus was on perceptual activities where a visual stimulus or target image/object was present. Sketching was viewed as a developmental process and students were graded on a Pass/Fail basis for this component as well. Details of each sketching task, informed by the work of Lane (2017), Lane \& Seery (2011) and Lane et al. (2009, 2011, 2012), are provided in Table 3.

\section{Results}

Over the 4 year period from 2014 to 2017, students entering the Technology Teacher program completed the PSVT:R test at the start of the semester and again thirteen weeks later at the end of the semester. The pre and post-intervention spatial scores are shown in Tables 4 and 5 below.

\section{Overall spatial performance}

In total across all 4 years of data collection, 362 students completed both the pre and post-test. A paired samples t-test was conducted to evaluate the impact of the intervention on students' scores on the Purdue Spatial Visualization Test of Rotations (PSVT:R). The maximum score on the PSVT:R is 30. There was a statistically significant increase in spatial performance from Pre-test $(M=20.86, S D=4.93)$ to Post-test $(\mathrm{M}=24.43, \mathrm{SD}=4.26), \mathrm{t}(362)=18.473, p<0.0001$ (two-tailed). The mean increase in spatial scores was 3.56 with a $95 \%$ confidence interval ranging from 3.18 to 3.94 . The eta squared statistic (0.49) indicated a large effect size. This significant increase highlights the benefit of integrating targeted spatial development tools and strategies on a whole class level for all ability levels. We believe that working through the intervention activities was beneficial for all of the pre-service teachers as it exposed them to the tools and strategies that they could adapt and employ in their secondary school teaching in the future.

It is also worth noting that the average post-intervention score for the pre-service Technology teachers at the University of Limerick (23.89) is similar to the scores of first-year Engineering students at Michigan Tech University on enrolment to the programme (Sorby et al., 2018), further highlighting a gap between Irish and US students.

\section{Gender performance}

We conducted two paired samples t-tests to evaluate the impact that the spatial intervention had on gender performance. For females, there was a statistically significant increase in spatial scores from Pre-test $(M=17.59, \mathrm{SD}=5.67)$ to Post-test $(\mathrm{M}=23.53, \mathrm{SD}=3.94), \mathrm{t}$ $(16)=4.182, p<0.001$ (two-tailed). The mean increase in scores was 5.94 with a $95 \%$ confidence interval ranging from 2.93 to 8.95 . The eta squared statistic $(0.52)$ indicated a large effect size. This brings the females to a similar level with the comparison (non-intervention) female group at Michigan Tech where the mean score was 23.4 (Sorby et al., 2018). 
Table 3 Details of perceptual sketching activities

Activity-Purpose Sketch

Week $1-2 \mathrm{D}$ to $2 \mathrm{D}$ Grid Sketch

The students were provided with a target sketch and a blank sheet with grid

Instruction was provided in relation to 'seeing' the geometry to include shape, proportion and relationships

Students 'copied' the drawing at a scale of 1:1 using their short-term memory to visualize and memorize the original and then retrieve and communicate on the blank grid

Students were required to work at their own pace with no time limit

Week 2-2D to 2D Grid Scaled Sketch

This was similar to the Week 1 activity; however, time, scale and hatching were introduced

The target sketch was shown on a $2 \mathrm{~m} \times 2 \mathrm{~m}$ projector screen and students were required to scale this down to their A4 sheet

A time limit of $40 \mathrm{~min}$ was used and each square on the grid was revealed at approximately 2-min intervals

Students were provided with tips and information relating to hatching before the activity commenced

Week 3 and 4-2D to 2D Rendering

An image of a sphere, cone, cylinder and cube were shown to the students on the $2 \mathrm{~m} \times 2 \mathrm{~m}$ projector screen with no grid present

Students were required to use a sighting method with their pencils to establish the scale of the sketch

The students were then provided with tips in relation to different values that can be drawn using a pencil and subsequent to this they rendered their sketch

Week 5-2D to 2D Negative Space and Rendering

The silhouette of a caricature was initially shown to the students on the $2 \mathrm{~m} \times 2 \mathrm{~m}$ projector screen with no grid present

Students were required to use a sighting method with their pencils to establish the scale of the sketch

Once the outline figure/negative space was sketched, the geometry within was revealed and this was sketched and rendered

The important aspects introduced in this activity were sighting scale, the concept of negative space and rendering

Week 6 and 7-3D to 2D Conversion

Students used the snap cubes from the Sorby intervention and sketched these in a number of orientations in space

A picture plane was utilized to help the student's convert the 3D object on to the $2 \mathrm{D}$ 'picture plane'

Week 8, 9 and $10-3 \mathrm{D}$ to 2D Conversion

Using all the strategies learned throughout the previous exercises, students sketched a number of physical objects where they were required to sight and imagine the 'picture plane'

These objects and buildings varied in size and shape
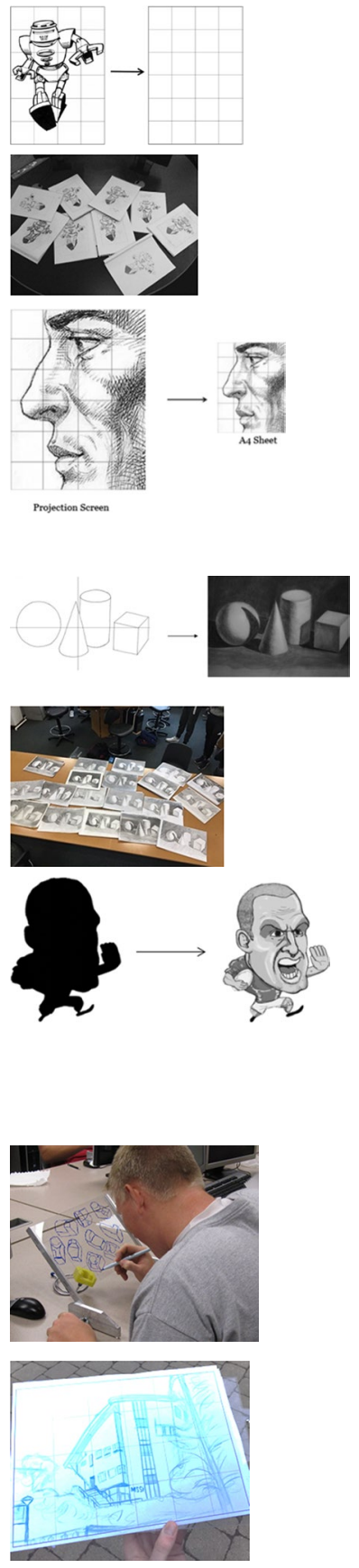
Table 4 Pre-Intervention PSVT:R scores on entry to program 2014-2017

\begin{tabular}{|c|c|c|c|c|c|c|c|c|c|c|c|c|c|c|c|}
\hline & \multicolumn{3}{|c|}{$\begin{array}{l}2014 \text { (Start of } \\
\text { Year) }\end{array}$} & \multicolumn{3}{|c|}{$\begin{array}{l}2015 \text { (Start of } \\
\text { Year) }\end{array}$} & \multicolumn{3}{|c|}{$\begin{array}{l}2016 \text { (Start of } \\
\text { Year) }\end{array}$} & \multicolumn{3}{|c|}{$\begin{array}{l}2017 \text { (Start of } \\
\text { Year) }\end{array}$} & \multicolumn{3}{|c|}{$\begin{array}{l}\text { 2014-2017 (Start } \\
\text { of Year) }\end{array}$} \\
\hline & $\mathrm{n}$ & Mean & SD & $\mathrm{n}$ & Mean & SD & $\mathrm{n}$ & Mean & SD & $\mathrm{n}$ & Mean & SD & $\mathrm{n}$ & Mean & SD \\
\hline Male & 114 & 20.98 & 4.74 & 119 & 20.92 & 4.84 & 79 & 21.51 & 5.27 & 75 & 20.53 & 4.90 & 387 & 20.98 & 4.90 \\
\hline Female & 7 & 16.43 & 3.99 & 2 & 16.5 & 4.95 & 3 & 19.67 & 2.52 & 7 & 17.86 & 7.73 & 19 & 17.47 & 5.36 \\
\hline Total & 121 & 20.72 & 4.81 & 121 & 20.85 & 4.85 & 82 & 21.44 & 5.20 & 82 & 20.30 & 5.19 & 406 & 20.82 & 4.97 \\
\hline
\end{tabular}

Table 5 Post Intervention PSVT:R scores at end of semester 1 2014-2017

\begin{tabular}{|c|c|c|c|c|c|c|c|c|c|c|c|c|c|c|c|}
\hline & \multicolumn{3}{|c|}{$\begin{array}{l}2014 \text { (End of } \\
\text { Year) }\end{array}$} & \multicolumn{3}{|c|}{$\begin{array}{l}2015 \text { (End of } \\
\text { Year) }\end{array}$} & \multicolumn{3}{|c|}{$\begin{array}{l}2016 \text { (End of } \\
\text { Year) }\end{array}$} & \multicolumn{3}{|c|}{$\begin{array}{l}2017 \text { (End of } \\
\text { Year) }\end{array}$} & \multicolumn{3}{|c|}{$\begin{array}{l}2014-2017 \text { (End } \\
\text { of Year) }\end{array}$} \\
\hline & $\mathrm{n}$ & Mean & SD & $\mathrm{n}$ & Mean & SD & $\mathrm{n}$ & Mean & SD & $\mathrm{n}$ & Mean & SD & $\mathrm{n}$ & Mean & SD \\
\hline Male & 102 & 25.18 & 3.98 & 102 & 24.75 & 3.98 & 113 & 22.71 & 5.21 & 92 & 22.97 & 4.69 & 409 & 23.89 & 4.62 \\
\hline Female & 6 & 23.33 & 5.89 & 2 & 22.50 & 4.95 & 4 & 20.00 & 4.24 & 7 & 23.86 & 3.29 & 19 & 22.74 & 4.46 \\
\hline Total & 108 & 25.07 & 4.09 & 104 & 24.71 & 3.98 & 117 & 22.62 & 5.19 & 99 & 23.03 & 4.60 & 428 & 23.84 & 4.62 \\
\hline
\end{tabular}

For male students, there was a statistically significant increase in spatial scores from Pre-test $(M=21.02, S D=4.84)$ to Post-test $(M=24.47, S D=4.27), t(345)=18.287$, $p<0.0001$ (two-tailed). The mean increase in scores was 3.45 with a $95 \%$ confidence interval ranging from 3.08 to 3.82 . The eta squared statistic $(0.49)$ indicated a large effect size. This post-intervention score is slightly below the male comparison (nonintervention) group reported by Sorby et al. (2018) where the mean score was 25.36.

In order to compare the mean scores of male and female students in the PSVT:R we conducted an independent samples t-test for the pre and post intervention scores. A significant difference in scores was observed for the pre-test where males $\mathrm{M}=20.98, \mathrm{SD}=4.90$ and females $\mathrm{M}=17.47, \mathrm{SD}=5.36$; $\mathrm{t}(404)=3.03, p=0.01$ (2-tailed). The magnitude of the differences in the means (mean difference $=3.51,95 \%$ ) was small (eta squared $=0.02$ ). There was no significant difference in scores observed for the post-test where males $M=23.89$, $\mathrm{SD}=4.62$ and females $\mathrm{M}=22.74, \mathrm{SD}=4.45 ; \mathrm{t}(426)=1.07, p=0.29$ (2-tailed).

The results show a greater improvement for females who started from a lower baseline and yet recorded similar spatial scores to males at the end of the semester. The PSVT:R scores highlight that students entering the Technology Teacher preparation programme in Ireland have lower spatial scores than the Engineering students at Michigan Tech University.

\section{Spatial visualization scores and graphics problem-solving}

We conducted a correlation analysis between the spatial scores (pre and post) and the scores in the end of semester graphical problem-solving exam for DCG 1. We wanted to establish if the pre and post spatial scores predicted performance in this exam. A sample question from the exam is shown in Fig. 4 below. 
Fig. 4 Sample question from DCG1 graphical problem-solving exam

\section{Question 7 (5 marks)}

Given are the projections of a machine component. Sketch a pictorial view of the component in the space below.
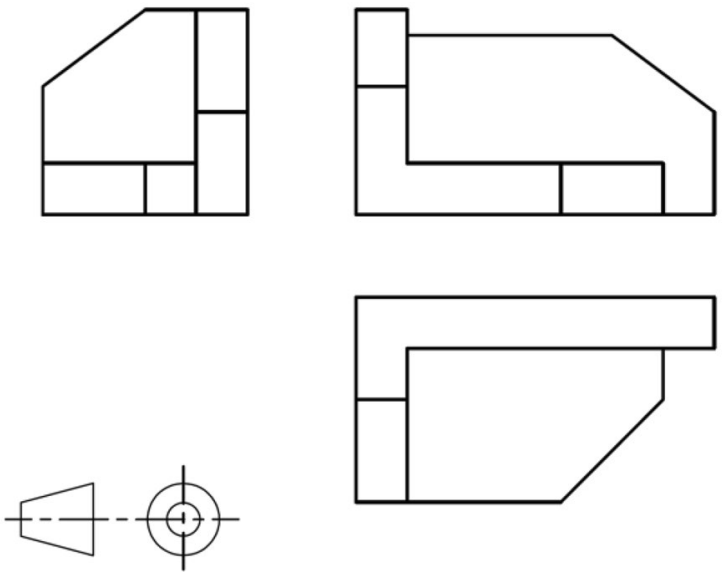

The relationship between pre and post-intervention spatial scores and the end of semester graphics exam was investigated using Pearson product-moment correlation coefficient. Preliminary analyses were performed to ensure no violation of the assumptions of normality, linearity and homoscedasticity. In terms of pre-intervention scores and scores in the problem-solving exam, there was a small, positive correlation between the two variables, $\mathrm{r}=0.225, \mathrm{n}=398, p<0.01$, with high spatial scores at pre-intervention stage associated with high scores in the exam. When we examined the relationship between post-intervention scores and scores in the problem-solving exam, we also found a small, positive correlation between the two variables, $\mathrm{r}=0.202, \mathrm{n}=411, p<0.01$, with high levels of scores in the PSVT:R at post-intervention stage associated with higher scores in the end of semester exam.

These small correlations suggest that other factors such as problem-solving, flexibility, confidence, experience and motivation may also be impacting performance on these exams.

\section{Course performance}

We examined the impact of the infused interventions on overall performance in the DCG course. The number of Fail grades from 2010 to 2019 are shown in Fig. 5. It should be noted that the primary data used in this paper for the intervention is only for 2014-2017 but the intervention remained the same in 2018 and 2019.

It can be seen that when the interventions were first introduced in 2014 that the failure rate initially remained fairly high. We examined Student Evaluation of Teaching (SET) reports and other evaluations of teaching and found that while students appeared to enjoy the module and found it beneficial, concerns were raised about the high number of contact hours and this was resulting in a heavy workload for the students.

In 2016, we changed the sketching lab and spatial skills lab to a blended classroom approach and only invited students who scored below a threshold of 18/30 in the PSVT:R to a face to face class. The remaining students completed the Spatial Thinking and 


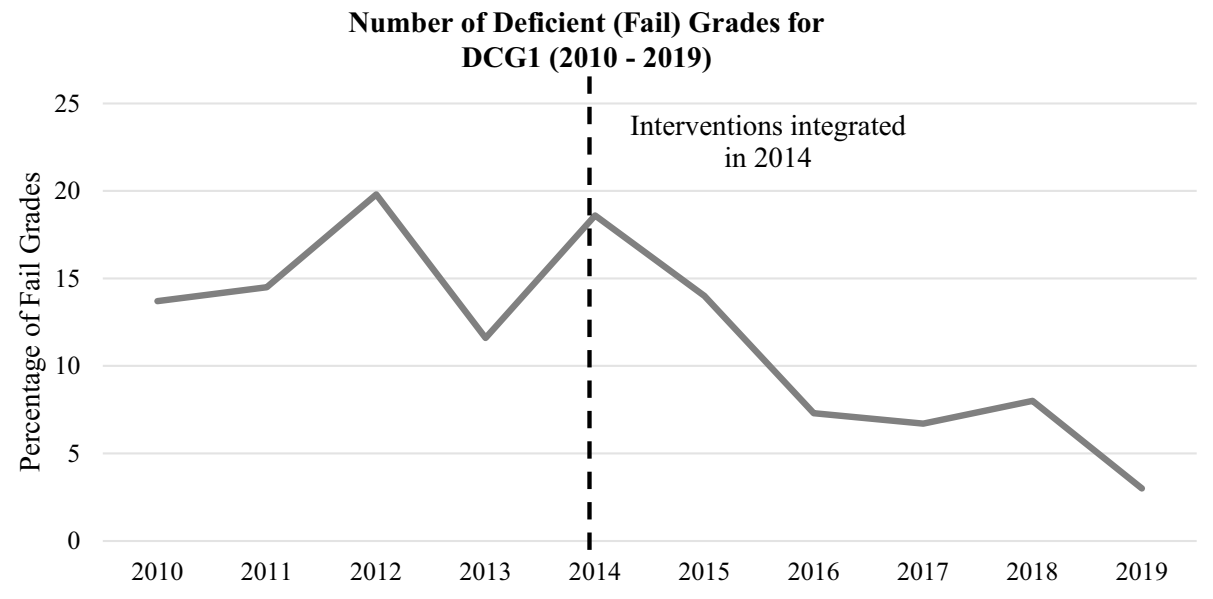

Fig. 5 Percentage of students who failed DCG1

sketching activities in their independent time with the aid of online videos provided by the course teaching team. This gave students more flexibility to arrange their own schedules. This appears to have made a positive impact on the student experience with improved overall course performance observed.

\section{General discussion}

In this paper, we have described why it was necessary to infuse a spatial intervention within a pre-service Technology Teacher Education programme. While the pressure to address and reflect on the high failure rate of students initially came from university administration, who expressed concerns about poor retention rates in the programme, the findings from our study highlight the positive impact that the intervention had. As Higher Education is increasingly being viewed as a global commodity (Naidoo, 2003), there is growing pressure on universities to ensure that certain performance metrics are being met. This top down pressure (Blackmore, 2009; Goldfarb \& Henrekson, 2003) combined with the growing number of students pursuing higher level education with diverse backgrounds and abilities (Jamelske, 2009), means that many university course leaders and teaching staff are being forced to examine the merits of integrating interventions to ensure students have the best possible chance of succeeding. In the case of the study presented in this paper, this top down pressure resulted in a positive outcome for both the students and the university as spatial skills were significantly improved in addition to improved course performance. Without this pressure from the university administration there is a possibility that the course team might not have realised the significant spatial deficit of students entering the Technology Teacher preparation programme.

In progressing the research agenda relating to the development of spatial skills in schools and colleges (Janelle, 2014), this study has shown how a blended spatial skills intervention, incorporating the Sorby workbook and supplemental sketching activities, has resulted in a significant improvement in spatial performance within Technology Education. To the best of our knowledge, this study is the first to show that a spatial intervention can 
be successfully infused within an existing curriculum for pre-service Technology Teachers and which has resulted in improved spatial performance of the students in the programme. While our study contributes to the knowledge base around the effectiveness of spatial training within pre-service teachers education programmes, it should be noted that there is need for further research in this area. The PSVT:R instrument only provides a measure of student's ability to rotate objects by given parameters. It does not measure other factors of spatial cognition such as closure, speed, scanning, imagery and so on. These have been described by Buckey et al. (2018) and are worth taking into consideration when measuring the impact of spatial interventions on performance in discipline specific tasks. Furthermore, other aspects such as; student motivation, anxiety, self-efficacy, previous subject experience and prerequisite content knowledge, all impact performance in problem-solving tasks. Therefore, the results in end of semester exams and overall module performance should be examined with these variables in mind.

A significant finding from this study was that female students were able to bridge a large gap in spatial performance compared to male students after completing the spatial activities. Based on existing research relating to gender differences in spatial performance, particularly for mental rotation tasks, it did not come as a surprise that the females performed lower on the timed spatial pre-test. However, the improvement in spatial scores at the post-intervention stage was significant for both males and females, and females were able to successfully bridge the pre-test gap with males. This highlights the value in ensuring that females are provided with the necessary supports to address potential spatial deficits. It also puts a spotlight on the experience of females in secondary schools and in their day to day lives. Are males provided with opportunities for spatial skills development that females don't necessarily experience? It is clear that females can bridge the gaps in spatial performance but is it sustainable and acceptable that they will leave secondary school with ground to make up compared to their male counterparts? On the contrary, recent research by Toth and Campbell (2019) at an Irish university examined the impact of taking the time factor out of spatial tests. They found that no evidence of a significant gender difference when time was not a factor when taking a spatial test. However, it could be that removing the time factor means that females can employ a less efficient, analytical method for problem-solving and are not truly drawing on their mental rotation skills. In fact, the original authors of the PSVT:R (Bodner \& Guay, 1997) advocated for the use of strict time limits in taking the test because they felt that extending the time led to measuring something other than true mental rotation skills. Due to the link they observed between speed and true mental rotation strategies in problem-solving, they revised the original PSVT:R used in this study (30 items over $20 \mathrm{~min}$ ) to a test consisting of 20 items to be administered over a 10 min time period. This also highlights a need for future research in the area.

There appears to be some differences in the international literature in relation to the spatial skills of STEM teachers. Atit et al. (2018) have reported that students with strong spatial skills are attracted into STEM teaching careers while Moore-Russo et al. (2012) have reported that Mathematics student teachers often struggle with spatial thinking skills. In this study in Ireland, we found that pre-service technology teachers consistently have underdeveloped spatial skills on entry to their program of study when compared with Engineering students at Michigan Tech University in the USA. This forces us to shine a spotlight on the secondary school experiences of students and the nature of the school curriculum across different countries. While the majority of Irish pre-service Technology teachers have experience in 'hands-on' subjects such as Woodwork and Metalwork in school, their struggles with spatial skills appear to persist. Perhaps it is the case that the pre-service Technology Teachers in this study are among the strongest 
spatial learners transitioning from Irish secondary schools to university and that students entering other programmes may have even lower spatial abilities. On the contrary, it should also be considered that entry to pre-service Technology Teacher programmes does not require grades in 'higher-level Mathematics' from secondary school but entry to mainstream Engineering programmes in most Irish universities does require students to have taken 'higher-level Mathematics' at secondary school. As spatial skills and mathematics performance have been shown to be significantly correlated (Atit et al., 2020), future research should look at the nature of the curricula offered in secondary schools on a national and international level to examine what is working and what is not in terms of spatial skill development.

\section{Educational implications}

We found in this study that spatial interventions can be successfully integrated into a Technology Teacher education programme with significant positive effects. While this further highlights that spatial skills are malleable, it must be questioned if it is sustainable for colleges and universities to integrate such interventions in the future. If students entered college and university with better spatial skills, would this enable them to engage more deeply in their studies? Would they be in a better position to engage in advanced spatial problemsolving and reasoning from the beginning? What impact could initial higher spatial skills have on academic performance and the advancement of different STEM disciplines?

Perhaps it is time to shift the focus towards secondary schools and help teachers develop strategies and skills to integrate spatial thinking across different disciplines. Lane et al. (2019) have examined this and have described potential challenges around establishing who is responsible for spatial thinking in secondary schools. In order for any real progress to be made in secondary schools, future research needs to consider the role of different disciplines and how a collective effort can be made to develop spatial thinking across the curriculum. Although we believe it is likely that many of the Technology Education teachers who graduated from the programme at UL will go on to incorporate a spatial thinking focus or exercises in their future secondary teaching roles, it is unclear if this would have a significant national impact on the spatial skills development of all students. In Ireland, similar to the situation in most other countries, a small percentage of students overall enrol in Technology subjects in secondary school and an even smaller percentage of girls enrol in these courses.

Finally, the impact of COVID on the spatial learning experience should be considered. As many schools have been forced to go online, this has meant that much learning is happening on screen with a reduction in the amount of hands-on activities. While students who already have well-developed spatial skills might adjust well to online spatial learning, it might prove more difficult for the weaker students who need classroom contact time and need to physically manipulate objects that are available in classrooms. How do we ensure that learning experiences involving physical manipulation and practical activities are maintained? In secondary schools, practical subjects such as Woodwork and Metalwork have been significantly impacted by COVID as much of the hands-on learning cannot be done at home. What impact would the reduction of physical, hands-on learning have on the development of spatial skills? There is much to consider for education provision, the development of technological capability and spatial skills in a post-COVID world. 


\section{Conclusions}

Similar to the USA, this study has found evidence to suggest a 'missing link' possibly exists in the Irish Education system in relation to Spatial Thinking. While we found that the spatial performance of pre-service Technology teachers can be improved with targeted instruction and learning activities, our findings have raised more questions than answers. There is significant potential for international collaborations across the STEM teacher education domain to examine different aspects of curriculum, pedagogy, and education policy with a view to addressing the 'missing link' that exists in relation to spatial skills development. While most in the STEM disciplines recognize the value in having students who are strong spatial thinkers, there is currently no systematic instruction in developing these skills in our pre-college education systems. This hit-or-miss strategy often means that some students, particularly women, begin their post-secondary studies at a disadvantage. If we are to achieve true gender equity in the STEM fields, it is important that we employ a more explicit strategy for spatial skills development, particularly in our teacher preparation programs. The study described here presents a "first-step" in the process of infusing spatial skills instruction in pre-college education. By designing and implementing a spatial skills intervention for students in a Technology Teacher education programme, not only have we improved their overall success as undergraduate students, but hopefully we have also started down the path towards improved spatial instruction in secondary schools.

Funding Open Access funding provided by the IReL Consortium.

Open Access This article is licensed under a Creative Commons Attribution 4.0 International License, which permits use, sharing, adaptation, distribution and reproduction in any medium or format, as long as you give appropriate credit to the original author(s) and the source, provide a link to the Creative Commons licence, and indicate if changes were made. The images or other third party material in this article are included in the article's Creative Commons licence, unless indicated otherwise in a credit line to the material. If material is not included in the article's Creative Commons licence and your intended use is not permitted by statutory regulation or exceeds the permitted use, you will need to obtain permission directly from the copyright holder. To view a copy of this licence, visit http://creativecommons.org/licenses/by/4.0/.

\section{References}

Anderson, J. O., Lin, H.-S., Treagust, D. F., Ross, S. P., \& Yore, L. D. (2007). Using large-scale assessment datasets for research in science and mathematics education: Programme for international student assessment (PISA). International Journal of Science and Mathematics Education, 5, 591-614. https:// doi.org/10.1007/s10763-007-9090-y

Atit, K., Miller, D. I., Newcombe, N. S., \& Uttal, D. H. (2018). Teachers' spatial skills across disciplines and education levels: Exploring nationally representative data. Archives of Scientific Psychology, 6(1), 130-137. https://doi.org/10.1037/arc0000041

Atit, K., Power, J. R., Veurink, N., Uttal, D. H., Sorby, S., Panther, G., Msall, C., Carr, M., Fiorella, L., \& Carr, M. (2020). Examining the role of spatial skills and mathematics motivation on middle school mathematics achievement. International Journal of STEM Education. https://doi.org/10.1186/ s40594-020-00234-3

Bennett, G. K., Seashore, H. G., \& Wesman, A. G. (1973). Differential aptitude tests, forms $S$ and T. The Psychological Corporation.

Blackmore, J. (2009). Academic pedagogies, quality logics and performative universities: Evaluating teaching and what students want. Studies in Higher Education, 34(8), 857-872. https://doi.org/10.1080/ 03075070902898664 
Bodner, G., \& Guay, R. B. (1997). The purdue visualization of rotations test. The Chemical Educator, 2(4), 1-17. https://doi.org/10.1007/s00897970138a

Buckley, J., Seery, N., \& Canty, D. (2018). A heuristic framework of spatial ability: A review and synthesis of spatial factor literature to support its translation into STEM education. Educational Psychology Review, 30, 947-972. https://doi.org/10.1007/s10648-018-9432-z

Buckley, J., Seery, N., \& Canty, D. (2019). Investigating the use of spatial reasoning strategies in geometric problem solving. International Journal of Technology and Design Education, 29, 341-362. https://doi. org/10.1007/s10798-018-9446-3

Card, D., \& Payne, A. A. (2020). high school choices and the gender gap in STEM. Enconomic Inquiry, 59(1), 9-28. https://doi.org/10.1111/ecin.12934

Casey, M. B., Nuttall, R. L., \& Pezaris, E. (1997). Mediators of gender differences in mathematics college entrance test scores: A comparison of spatial skills with internalized beliefs and anxieties. Developmental Psychology, 33(4), 669-680. https://doi.org/10.1037/0012-1649.33.4.669

CEEB. (1939). Special aptitude test in spatial relations. College Entrance Examination Board.

Close, S., \& Shiel, G. (2009). Gender and PISA mathematics: Irish results in context. European Educational Research Journal, 8(1), 20-33. https://doi.org/10.2304/eerj.2009.8.1.20

Cooper, M. M., Stieff, M., \& DeSutterc, D. (2017). Sketching the invisible to predict the visible: From drawing to modeling in chemistry. Topics in Cognitive Science, 9, 902-920. https://doi.org/10. $1111 /$ tops. 12285

Delahunty, T., Seery, N., \& Lynch, R. (2020). Exploring problem conceptualization and performance in STEM problem solving contexts. Instructional Science. https://doi.org/10.1007/ s11251-020-09515-4

Duffy, G., Farrell, S., Harding, R., Behan, A., Mac Raighne, A., Howard, R., Nevin, E., Bowe, B. (2015). The effects of spatial skills and spatial skills training on academic performance in STEM education. In The 6th research in engineering education symposium (REES, 2015). Dublin, Ireland.

Duffy, G., Sorby, S., \& Bowe, B. (2020). An investigation of the role of spatial ability in representing and solving word problems among engineering students. Journal for Engineering Education. https://doi.org/10.1002/jee.20349

Gagnier, K. M., Atit, K., Ormand, C. J., \& Shipley, T. F. (2016). Comprehending 3D diagrams: Sketching to support spatial reasoning. Topics in Cognitive Science, 9(4), 883-901. https://doi.org/10. $1111 /$ tops. 12233

Goktepe Yildiz, S., \& Ozdemir, A. S. (2020). The effects of engineering design processes on spatial abilities of middle school students. International Journal of Technology and Design Education, 30, 127-148. https://doi.org/10.1007/s10798-018-9491-y

Goldfarb, B., \& Henrekson, M. (2003). Bottom-up versus top-down policies towards the commercialization of university intellectual property. Research Policy, 32(4), 639-658. https://doi.org/10.1016/ S0048-7333(02)00034-3

Gonzales, R., Ferns, G., Vorstenbosch, M. A. T. M., \& Smith, C. F. (2020). Does spatial awareness training affect anatomy learning in medical students? Anatomical Sciences Education, 13(6), 707-720. https://doi.org/10.1002/ase.1949

Goodchild, M. F., \& Janelle, D. G. (2010). Toward critical spatial thinking in the social sciences and humanities. GeoJournal, 75, 3-13. https://doi.org/10.1007/s10708-010-9340-3

Guay, R. B. (1977). Purdue spatial visualization test: Rotations. West Lafayette, IN: Purdue Research Foundation.

Hegarty, M. (2014). Spatial thinking in undergraduate science education. Spatial Cognition \& Computation, 14, 142-167. https://doi.org/10.1080/13875868.2014.889696

Hegarty, M., Uttal, D., Stieff, M., Lowrie, T., Vosniadou, S. (2017). Educating spatial thinking for STEM success. In G. Gunzelmann, Howes, A., Tenbrink, T., Davelaar, E. (Ed.), 39th Annual meeting of the cognitive science society (pp. 27-28). London, UK.

Herborn, K., Stadler, M., Mustafić, M., \& Greiff, S. (2020). The assessment of collaborative problem solving in PISA 2015: Can computer agents replace humans? Computers \& Human Behaviour, 104, 105624

Jamelske, E. (2009). Measuring the impact of a university first-year experience program on student GPA and retention. Higher Education, 57(3), 373-391. Retrieved from https://www.jstor.org/stable/ 40269128

Janelle, D. G., Hegarty, M., \& Newcombe, N. S. (2014). Spatial thinking across the college curriculum: A report on a specialist meeting. Spatial Cognition \& Computation: An Interdisciplinary Journal, 14(2), 124-141. https://doi.org/10.1080/13875868.2014.888558

Lane, D. (2011). Developing sketching expertise within technology education. (Ph.D.). University of Limerick, Limerick. 
Lane, D. (2017). Drawing and sketching: Understanding the complexity of paper-pencil interactions within technology education. In M. de Vries (Ed.), Handbook of technology education. Springer international handbooks of education. Cham: Springer.

Lane, D., Hamlin, AJ., Veurink, N., Seery, N. (2012). The role of observational sketching in forming and manipulating graphical libraries. In A. S. f. E. Education (Ed.), ASEE Annual Conference. San Antonio, TX.

Lane, D., \& Seery, N. (2011). Freehand sketching as a catalyst for developing concept driven competencies. Engineering Design Graphics Journal, 75(1), 2-25.

Lane, D., Lynch, R., \& McGarr, O. (2019). Problematizing spatial literacy within the school curriculum. International Journal of Technology and Design Education. https://doi.org/10.1007/ s10798-018-9467-y

Lane, D., Seery, N., \& Gordon, S. (2009). The understated value of freehand sketching in technology education. Engineering Design Graphics Journal, 73(3), 13-22.

Lin, H. (2016). Influence of design training and spatial solution strategies on spatial ability performance. International Journal of Technology and Design Education, 26(1), 123-131. https://doi.org/10.1007/ s10798-015-9302-7

Lippa, R., Collaer, M. L., \& Peters, M. (2010). Sex differences in mental rotation and line angle judgments are positively associated with gender equality and economic development across 53 nations. Archives of Sexual Behaviour, 39(4), 990-997.

Lowrie, T., Logan, T., \& Ramful, A. (2017). Visuospatial training improves elementary students' mathematics performance. British Journal of Educational Psychology, 87, 170-186. https://doi.org/10.1111/ bjep. 12142

Maeda, Y., \& Yoon, S. Y. (2013). A meta-analysis on gender differences in mental rotation ability measured by the purdue spatial visualization tests: Visualization of rotations (PSVT:R). Educational Psychology Review, 25, 69-94. https://doi.org/10.1007/s10648-012-9215-x

Moore-Russo, D., Viglietti, J. M., Chiu, M. M., \& Bateman, S. M. (2012). Teachers' spatial literacy as visualization, reasoning, and communication. Teaching and Teacher Education, 29, 97-109.

Naidoo, R. (2003). Repositioning higher education as a global commodity: Opportunities and challenges for future sociology of education work. British Journal of Sociology of Education, 24(2), 249-259. https:// doi.org/10.1080/01425690301902

Newcombe, N. (2017). Harnessing spatial thinking to support stem learning. Retrieved from Paris, France

Newcombe, N. S. (2010). Picture this: Increasing math and science learning by improving spatial thinking. American Educator (Summer), 29-43.

Newcombe, N. S., \& Shipley, T. F. (2015). Thinking about spatial thinking: New typology, new assessments. In J. Gero (Ed.), Studying visual and spatial reasoning for design creativity. Dordrecht: Springer.

NRC. (2006). Learning to think spatially. Retrieved from Washington, DC:

OECD. (2014). PISA 2012 Results in Focus What 15-year-olds know and what they can do with what they know. Retrieved from Paris, France:

Power, J. R., \& Sorby, S. A. (2020). Spatial development program for middle school: Teacher perceptions of effectiveness. International Journal of Technology and Design Education. https://doi.org/10.1007/ s10798-020-09587-w

Price, G., \& Reid, D. (1990). A preliminary study into the investigation of the prediction of craftmanship skills in children. International Journal of Technology and Design Education, 1, 33-39. https://doi. org/10.1007/BF00420294

Šafhalter, A., Glodež, S., Šorgo, A., \& Ploj Virtič, M. (2020). Development of spatial thinking abilities in engineering 3D modeling course aimed at lower secondary students. International Journal of Technology and Design Education. https://doi.org/10.1007/s10798-020-09597-8

Smith, I. M. (1964). Spatial ability: Its educational and social significance. University of London Press.

Sorby, S. (2011). Developing spatial thinking workbook: Cengage.

Sorby, S., Veurink, N., \& Streiner, S. (2018). Does spatial skills instruction improve STEM outcomes? The answer is 'yes.' Learning and Individual Differences, 67, 209-222. https://doi.org/10.1016/j.lindif. 2018.09.001

Sorby, S. A. (2009). Educational research in developing 3-D spatial skills for engineering students. International Journal of Science Education, 31(3), 459-480.

Sorby, S. A., Leopold, C., \& Gorska, R. (1999). Cross-cultural comparisons of gender differences in the spatial skills of engineering students. Journal of Women and Minorities in Science and Engineering, 5(3), 279-291. https://doi.org/10.1615/JWomenMinorScienEng.v5.i3.50

Stieff, M., \& Uttal, D. (2015). How much can spatial Training Improve STEM Achievement? Educational Psychology Review, 27, 607-615. https://doi.org/10.1007/s10648-015-9304-8 
Stieff, M., Lira, M. E., \& Scopelitis, S. A. (2016). Gesture supports spatial thinking in STEM. Cognition and Instruction, 34(2), 80-99. https://doi.org/10.1080/07370008.2016.1145122

Toth, A., \& Campbell, M. J. (2019). Investigating sex differences, cognitive effort, strategy, and performance on a computerised version of the mental rotations test via eye tracking. Science and Reports. https://doi.org/10.1038/s41598-019-56041-6

Uttal, D. H., Miller, D.I., Newcombe, N.S. (2013). Exploring and enhancing spatial thinking: Links to achievement in science, technology, engineering, and mathematics? Current Directions in Psychological Science, 22(5), 367-373. Retrieved from https://www.jstor.org/stable/44318690

Uttal, D., Meadow, N. G., Tipton, E., Hand, L. L., Alden, A. R., Warren, C., \& Newcombe, N. S. (2013a). The malleability of spatial skills: A meta-analysis of training studies. Psychological Bulletin, 139(2), 352-402. https://doi.org/10.1037/a0028446

Veurink, N. L., \& Sorby, S. A. (2017). Longitudinal study of the impact of requiring training for students with initially weak spatial skills. European Journal of Engineering Education. https://doi.org/10.1080/ 03043797.2017.1390547

Wai, J., Lubinski, D., \& Benbow, C. P. (2009). Spatial ability for STEM domains aligning over 50 years of cumulative psychological knowledge solidifies its importance. Journal of Educational Psychology, 101(4), 817-835.

Wai, J., Uttal, DH. (2018). Why spatial reasoning matters for education policy. Retrieved from https://www. aei.org/research-products/report/why-spatial-reasoning-matters-for-education-policy/

Yonghong, J. (2008). Gender disparity in STEM disciplines: A study of faculty attrition and turnover intentions. Research in Higher Education, 49(7), 607-624.

Publisher's Note Springer Nature remains neutral with regard to jurisdictional claims in published maps and institutional affiliations. 